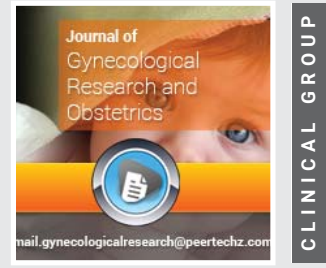

\section{Non-gestational primary choriocarcinoma of the ovary presentation of a clinical case}

\author{
Vargas-Hernandez Victor Manuel ${ }^{1,2 *}$, Machuca-Hernandez \\ Violeta Fabiola², Victor Manuel Vargas-Aguilar ${ }^{1}$, Agustin \\ Rodriguez Blaz ${ }^{1}$, and Jose Maria Tovar Rodriguez ${ }^{1}$
}

${ }^{1}$ Mexican Academy of Surgery, National Academy of Medicine of Mexico,

${ }^{2}$ Gynecology Service, Hospital Juárez de México,
Received: 06 December, 2021

Accepted: 23 December, 2021

Published: 24 December, 2021

*Corresponding author: Vargas-Hernandez Victor Manuel, Mexican Academy of Surgery, National Academy of Medicine of Mexico, Insurgentes Sur 6051403, Naples, 03810 CDMX, México, Tel: 5552179782 , 55746647; E-mail: vvargashernandez@yahoo.com.mx

Keywords: Non-gestational ovarian choriocarcinoma; Ectopic pregnancy; Diagnosis and treatment

Copyright: (c) 2021 Victor Manuel VH, et al. This is an open-access article distributed under the terms of the Creative Commons Attribution License, which permits unrestricted use, distribution, and reproduction in any medium, provided the original author and source are credited.

https://www.peertechzpublications.com

Check for updates

\begin{abstract}
Background: Ovarian germ cell tumors are derived from the primordial germ cells of the ovary, they can be benign or malignant. Non-gestational ovarian choriocarcinoma is extremely rare and aggressive that is of gestational or non-gestational origin, its prevalence is less than $0.6 \%$ of all ovarian germ cell tumors. Due to the rarity of the tumor, there is a lack of information on the clinical-pathological characteristics, diagnosis and treatment.
\end{abstract}

Objective: A case of non-gestational ovarian choriocarcinoma and a review of the literature are presented.

Clinical case: We present the case of a 20 -year-old woman who presented with an acute abdomen, due to abdominal pain and distention, with scant vaginal bleeding and pain on cervical mobilization; An ultrasound was performed with a right annex with a lesion measuring $114 \times 83 \times 79 \mathrm{~mm}$ and a total volume of $394 \mathrm{cc}$, heterogeneous with linear images inside punctiform and human chorionic beta-gonadotropin levels, elevated $112.337 \mathrm{mUI} / \mathrm{mL}$, the patient underwent an exploratory laparotomy with the finding of an ovarian tumor; performing salpingo-oophorectomy and the histopathological report of the definitive surgical specimen and immunohistochemical study, the diagnosis of non-gestational ovarian choriocarcinoma was made.

Conclusion: Non-gestational choriocarcinoma is an extremely rare malignant neoplasm that can present clinically as an acute abdomen and requires differential diagnoses. Management is the combination of surgery and adjuvant chemotherapy, our patient responded.

\section{Background}

Primary ovarian choriocarcinoma may arise from gestational tissue or pure germ cells of the ovary; it is known as gestational choriocarcinoma or non-gestational choriocarcinoma [1]. The estimated incidence of ovarian gestational choriocarcinoma is 1 : $369,000,000$ pregnancies, while non-gestational choriocarcinomas correspond to less than $0.6 \%$ of ovarian germ cell tumors, they comprise $2.1 \%$ of all germ cell malignancies ovarian, which makes this neoplasm extremely rare [2-4]; in PubMed from 1976 to 2021 there are 54 reports.

Furthermore, both gestational and non-gestational diseases exhibit identical clinical manifestations and histology. but difficult cases often require DNA analysis, clinical diagnostic criteria are unreliable, except in patients who are unable to conceive or who have never had sexual intercourse [5-9]. To differentiate them, it is necessary to determine whether there is a paternal contribution to the tumor genome. The tumor genetic polymorphism and comparison with those found in the patient and partner should define the presence or absence of paternal DNA and establish whether a tumor is gestational or not; only five cases have been reported of non-gestational pure ovarian choriocarcinoma diagnosed with polymorphic DNA analysis; Gestational choriocarcinoma shows broader variations in karyotype, the majority being aneuploid, and some in the hyperdiploid and hypotetraploid range. Many forms of chromosomal gains, losses, and rearrangements are 
seen, but no specific chromosomal abnormality has yet been identified [10].

A medical history of pregnancy, amenorrhea, or gestational trophoblastic disease can help determine the diagnosis. These types of tumors should be considered distinct entities with different therapeutic approaches, chemotherapy regimens, and prognosis associated with each disease; diagnostic criteria for non-gestational ovarian choriocarcinoma were performed in 1963; including absence of disease in the uterine cavity, pathological confirmation of the disease, and exclusion of molar pregnancy and intrauterine pregnancy $[11,12]$; in this case, all criteria were met. It is highly aggressive; It can develop as metastatic gestational choriocarcinoma from choriocarcinoma of the uterus or uterine tubes, or as primary gestational choriocarcinoma associated with ovarian pregnancy, or as a non-germ cell tumor of germ cells that differentiates towards trophoblastic structures; Gestational choriocarcinoma is associated with the spectrum of gestational trophoblastic disease. Non-gestational ovarian choriocarcinoma is associated with germ cell transformation. Both types of choriocarcinoma tend to develop early hematogenous metastases at different sites including the lung, liver, brain, bone, vagina, and other viscera $[4,13,14]$.

Compared with gestational choriocarcinomas, nongestational choriocarcinomas are relatively chemoresistant and are associated with a worse prognosis, especially in an advanced stage, early diagnosis and timely initiation of therapy is important, early diagnosis presents unique challenges in women of reproductive age [15].

\section{Presentation of the case}

A 20-year-old married woman, with no history of pregnancy, who was admitted to the hospital for colicky abdominal pain in the right iliac fossa with radiation to the right iliac fossa from moderate to severe with Visual Analogue Scale with nausea and vomiting treated with analgesics presenting slight improvement; It is requested, quantification of the beta fraction of gonadotropin with figures of 112,337 $\mathrm{mIU} / \mathrm{mL}$ and pelvic ultrasound with a report of a complex cyst of the right ovary without evidence of free fluid in the cul-desac; in relation to probable dysgerminoma or tumor of etiology to be determined; the hematic biometry with hemoglobin of 15.8 and hematocrit of 45, platelets of 313,000 , leukocytes of 11,300 and 2 bands; reason for which she is referred to Hospital Juárez de México and once hospitalized; on August 18, 2017; she presents low-cost symptoms; and the studies are repeated quantification of beta fraction of Human Chorionic Gonadotropin (hGC) greater than 5,000, hemoglobin of 18 grams, hematocrit of $47 \%$, leukocytes of 12,000 , platelets of 367,000 , lactic dehydrogenase of 473 , direct bilirubin of 0.8 and the 2.3 total; normal liver transaminases; Ultrasound reports uterus in anteversion of $79 \times 26 \times 31 \mathrm{~mm}$, homogeneous myometrium, endometrial thickness of $7.9 \mathrm{~mm}$ and right annex with lesion of $114 \times 83 \times 79 \mathrm{~mm}$ and total volume of $394 \mathrm{cc}$, heterogeneous with linear images in its interior punctiform, the ultrasound diagnosis was, probable right annex teratoma tumor cystic.
On physical examination, the patient with generalized pallor of the skin and integuments, hypotensive, tachycardic, diaphoretic, without cardiorespiratory compromise, globose abdomen due to abundant adipose panniculus, perstalsis present, pain on palpation in the right iliac fossa on bimanual touch, the uterus is delimited $8 \times 5 \mathrm{~cm}$, right annex, $12 \times 9 \mathrm{~cm}$ adnexal tumor, irregular, firm, pain on cervical mobilization, with spotting-shaped transvaginal hemorrhage, extremities without edema, normal tendon reflexes. According to the clinical presentation, imaging studies, on suspicion of ruling out ectopic pregnancy, an exploratory laparotomy was performed, with findings of the right annex of $20 \times 15 \mathrm{~cm}$ adhered to the uterus and sigmoid rectum without evidence of hemoperitoneum and a right salpingo-oophorectomy was performed for probable right ectopic pregnancy with hematic loss due to the surgical procedure of $40 \mathrm{cc}$ and sent to pathology for definitive histopathological study, during follow-up a control gonadotropin quantification was requested with the last report of $1103918.7 \mathrm{mUI} / \mathrm{mL}$. The histopathological results of the macroscopic surgical specimen were right salpingooophorectomy, with choriocarcinoma with extensive necrosis, $1 \mathrm{~cm}$ tumor extension to the ovarian surface not identified, lymphovascular invasion present and free surgical margins of the residual ovarian tumor with cystic follicles, Figure 1 and the report microscopic, Figures 2-4. A new hCG quantification is performed, negative head tomography and chest tomography with probable metastasis due to pulmonary nodule, in abdomen and pelvis, presence of peritoneal carcinomatosis, with free fluid and lumbar puncture reports negative for malignant cells and chemotherapy based on cisplatin and etoposide 5 sessions and the patient is disease-free after two years of follow-up.

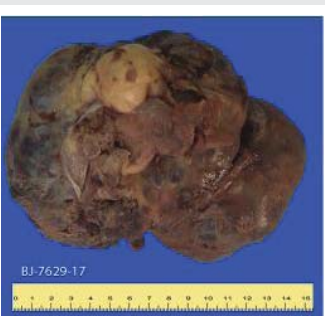

A

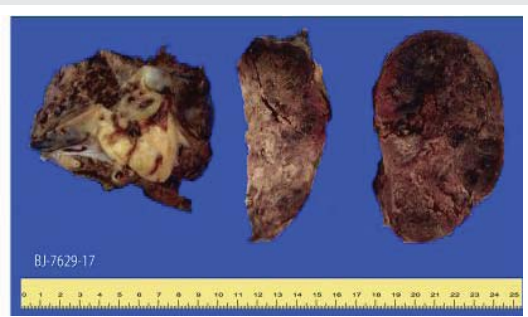

B
Figure 1: Histopathological report (8BJ-7629-19) Choriocarcinoma; A) tumor that forms a large solid gray hemorrhagic mass involving ovary and uterine tube; B) When the ovarian tumor is sectioned, a solid mass is observed with extensive areas of necrosis and hemorrhage, the ovarian surface when sectioned with hemorrhage cysts of different sizes.

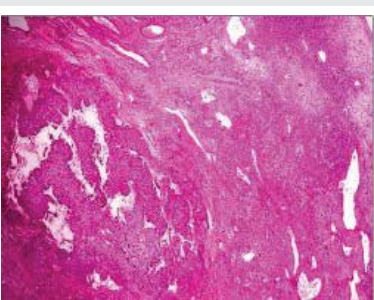

A

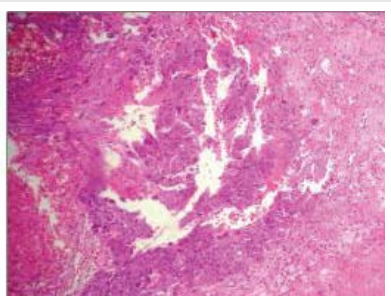

B
Figure 2: (BJ-7629-17). Choriocarcinoma: A) Ovarian panoramic view with extensive areas of hemorrhage, necrosis and nests of neoplastic germ cells (E\&E, original $\mathrm{x} 40$ ); B) a germinal neoplasm consisting of mononucleated trophoblast and syncytiotrophoblast cells is observed in the periphery of the blood channels (H\&E, original $x 100$ )

Citation: Victor Manuel VH, Violeta Fabiola MH, Vargas-Aguilar VM, Blaz AR, Tovar Rodriguez JM (2021) Non-gestational primary choriocarcinoma of the ovary presentation of a clinical case. J Gynecol Res Obstet 7(3): 050-054. DOI: https://dx.doi.org/10.17352/jgro.000105 


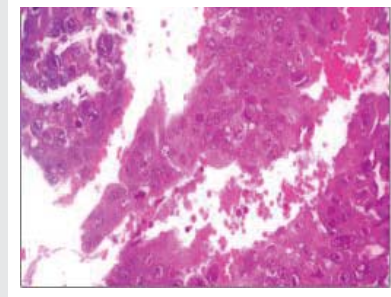

A

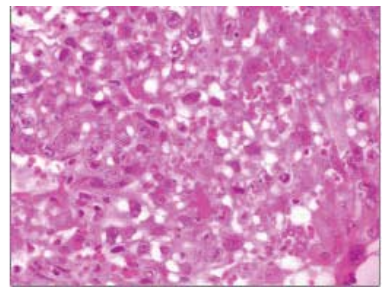

B
Figure 3: BJ-7629-17. Choriocarcinoma; A) syncytiotrophoblast, composed of large, basophilic, vacuolate cells with irregular borders; These cells contain multiple hyperchromatic nuclei, varying in shape and size (H\&E, original x400); B) mononucleated trophoblast, composed of cytoplasm and intermediate trophoblast, cells are medium-sized, polygonal, round, or oval with clear cytoplasm and sharp edges. Some cells have centrally located, small, round and hyperchromatic nuclei, others have larger vesicular nuclei with nucleolus and mitotic activity (H\&E, original $x 400)$.

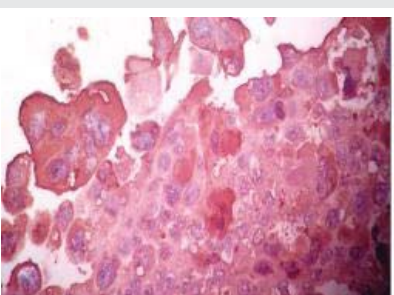

A

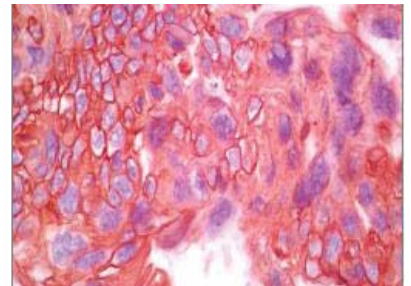

B
Figure 4: BJ-7629-17. Choriocarcinoma (original, x400); A) Positive cytoplasmic immunostaining for beta.hGC in syncytiotrophoblast cells B) Positive membranous immunostaining for CK AE1 / AE3 in cytotrofloblast cells.

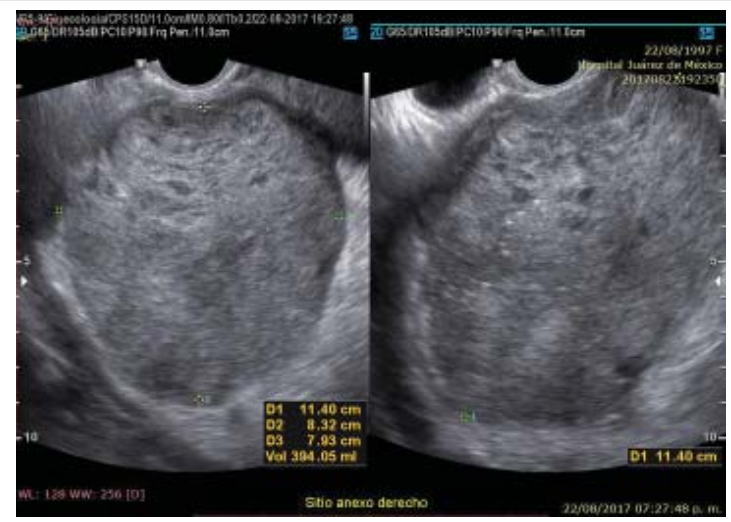

Photo 1: Transvaginal ultrasound. Right Annex. Heterogeneous echogenic tumor due to the presence of scattered irregular small hypoechoic images surrounded by echogenic tissue, as well as echogenic punctate images Dimensions of $114 \mathrm{x}$ $73 \times 89 \mathrm{~mm}$.

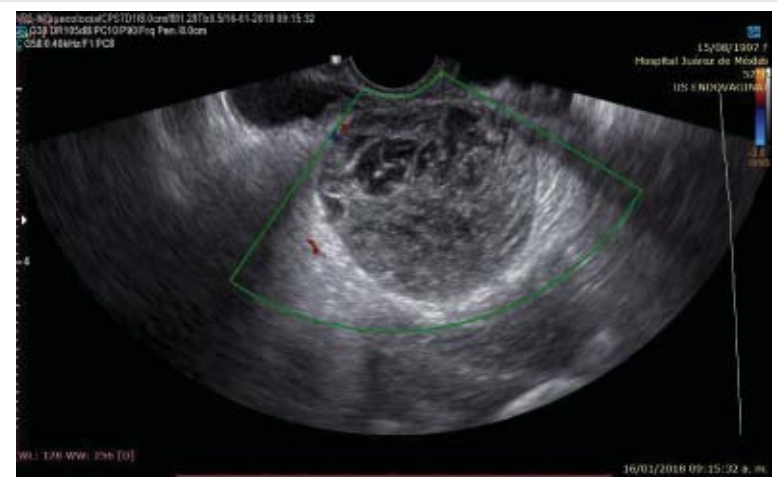

Photo 2: Transvaginal ultrasound. Right adnexal tumor, lesion without vascular flow in the Doppler modality.

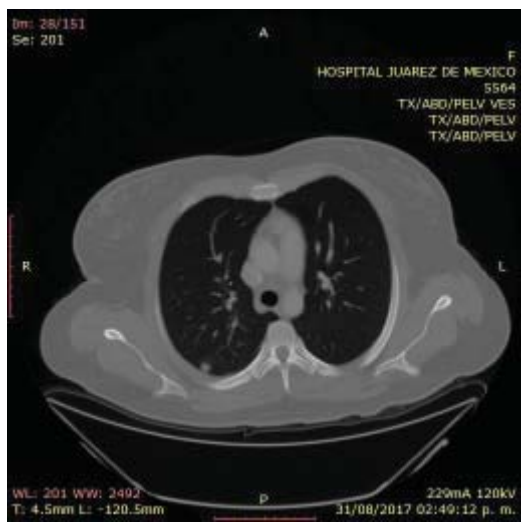

Photo 3: Thoracoabdominal computed tomography. Posterior basal pulmonary nodule on the right side of $11 \mathrm{~mm}$ in diameter with a pleural base.
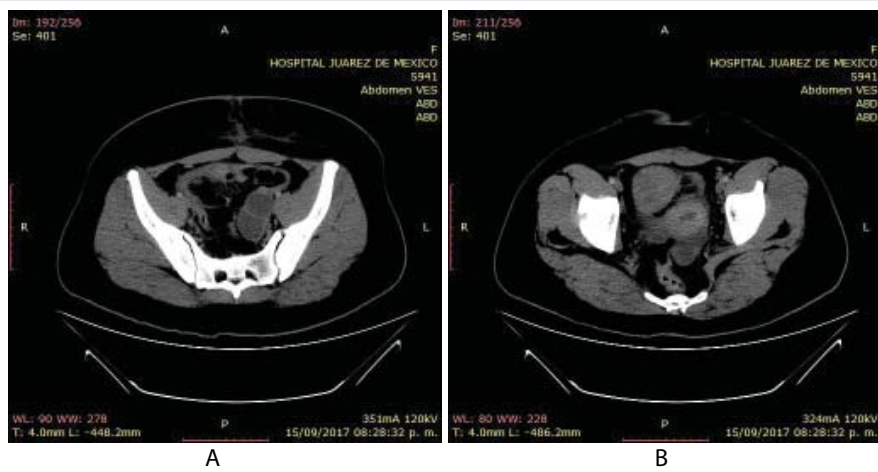

Photo 4: Abdominal computed tomography. Free intra-abdominal fluid (A). Left annex with the presence of two well-defined hypodense lesions with cystic behavior. Solid tumor with well-defined and delimited edges, located forward and to the right of the uterus, measuring $57 \times 49 \mathrm{~mm}$, which presents moderate enhancement (B).

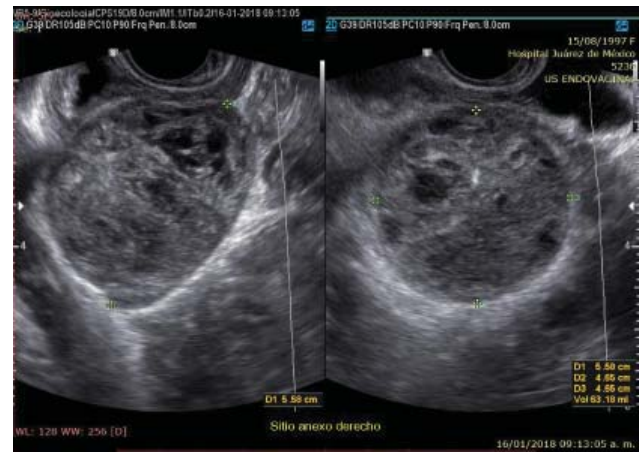

Photo 5: Transvaginal ultrasound. Mixed solid tumor with almost anechoic, small scattered areas surrounded by echogenic tissue. Dimensions $55 \times 46 \times 46 \mathrm{~mm}$.

\section{Discussion}

Non-gestational ovarian choriocarcinoma, which is not associated with pregnancy, is a rare germ cell tumor of high-grade malignancy that occurs more frequently in preadolescent women [11,16]; Its clinical manifestations of NGCO include vaginal bleeding, abdominal pain, and pelvic masses, most of which are misdiagnosed and initially treated for tumor torsion, ovarian tumor, or ovarian cancer $[4,13,14]$, as the case presented. The rarity of primary ovarian choriocarcinoma makes it a diagnostic challenge and generally an incidental finding in the surgical specimen of an ovarian tumor, the low incidence of these cases, a differential diagnosis should be 

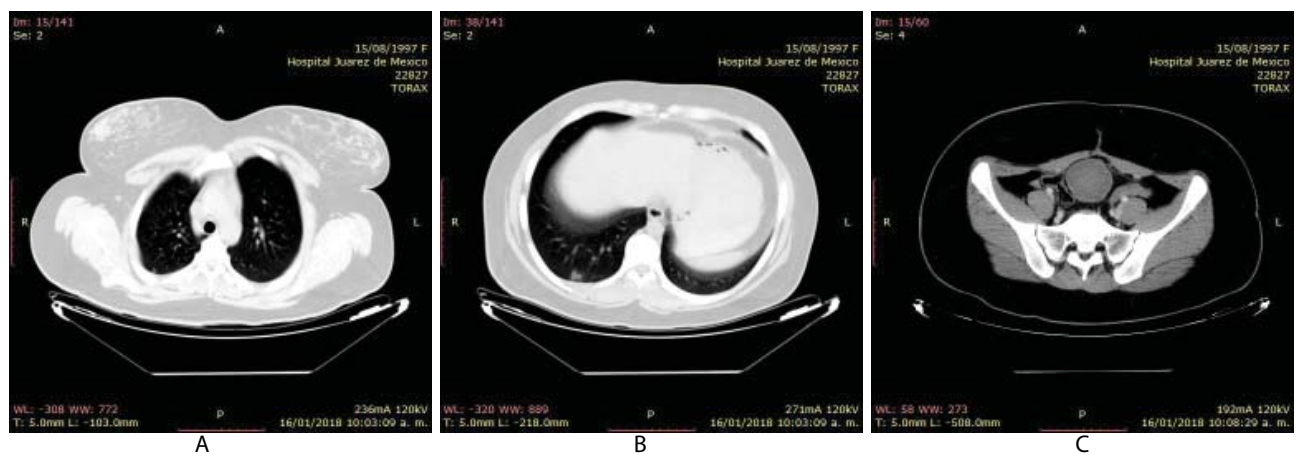

Photo 6: Thoracoabdominal computed tomography. Low density right lung nodules and poorly defined borders. One apical and one basal (A and B). Hypodense pelvic mass with defined borders with little reinforcement located above the bladder and in front of the uterus (C).

made in women of reproductive age who present with an acute abdomen and suspected complications of ectopic pregnancy [15]; for the symptoms of pelvic pain, positive pregnancy test, adnexal tumor and anemia; as the case presented; the majority of non-ovarian choriocarcinomas are histopathologically diagnosed after surgery (4); the best treatment for nongestational ovarian choriocarcinoma is surgery with adjuvant chemotherapy; however, they often have a poor prognosis $[10,13,14]$; a histopathological study is essential. The serum quantification of the beta-hCG fraction is decisive because it is not only the basis for diagnosis but also for prognosis [1-4]; The clinical case that we present was initially seen and referred to our hospital; with imaging studies and quantification of hGC; Due to the acute abdomen symptoms that he presented and the ultrasound report, emergency surgery was indicated; It is reported that the complications of tumors, causing an acute abdomen, which requires emergency surgery in 40 to $50 \%$ of cases, such as this case.

Choriocarcinomas, due to their great angioinvasion capacity, which facilitates their dissemination and encourages metastases to the lung, brain, liver and other organs, have early metastasis to the lung even in $80 \%$ of cases, in our case, pulmonary metastasis was diagnosed by imaging, confirming the great tumor vascular invasion; the majority die, even when diagnosed early to initiate appropriate chemotherapy, with a mortality rate of $10 \%$ to $15 \%[17,18]$. This report describes a case that simulated an ectopic pregnancy, which underwent surgery of the administration of chemotherapy; We report that the reproductive prognosis is favorable and treatment with conservative surgery does not affect fertility. Ovarian germ cell malignancies are sometimes associated with pregnancy or term pregnancies are achieved after uncomplicated treatment with healthy term infants [19].

Gestational choriocarcinoma shows wider variations in karyotype, the majority being aneuploid, and some in the hyperdiploid and hypotetraploid range. Many forms of chromosomal gains, losses, and rearrangements are seen, but no specific chromosomal abnormality has yet been identified. Pure non-gestational choriocarcinoma of the ovary is so rare that it is not known whether the prognosis is worse than gestational choriocarcinoma or not. Some articles reported that non-gestational choriocarcinoma of the ovary has a worse prognosis and is less sensitive to methotrexate-based chemotherapy regimens than gestational neoplasia. But they were not definitively diagnosed by DNA polymorphism analysis. It is important to clarify whether the tumor arose from a gestational or non-gestational origin to accurately understand the prognosis of this disease; nongestational ovarian choriocarcinoma has a less favorable prognosis than gestational type [20-24].

The non-gestational type is a rare germ cell tumor with trophoblastic differentiation. Intrauterine choriocarcinoma is the most common subtype. Few cases have also been reported involving other anatomical sites such as the ovary, fallopian tubes, and the abdominopelvic cavity [25].

The tumor has a marked tendency to metastasize early by dissemination to the blood, lungs $(80 \%)$, pelvis $(20 \%)$, vagina $(30 \%)$, liver $(10 \%)$ and other rare sites gastrointestinal tract, spleen and kidney; the central nervous system is rarely involved in the absence of pulmonary metastases; but, it is one of the main causes of death. Metastases are commonly hemorrhagic due to the innate ability of trophoblastic cells to invade and erode blood vessels [26].

As a consequence of its rarity and variability in reports, conclusive recommendations regarding the ideal therapy are lacking. In the future, definitive categorization is warranted, through DNA polymorphism analysis, and the creation of an international tumor registry for rare disease entities such as pure ovarian choriocarcinoma, in order to facilitate a better understanding of its etiology. and the standardization of therapy with optimization of results [27].

There are few case reports in our country and no case had been reported in our hospital; For this reason, we consider it important to report the form of presentation for its timely diagnosis, to improve the prognosis and survival of the patient. According to previous reports, it seems that pure ovarian choriocarcinoma responds well to the combination of surgical ablation and postoperative chemotherapy. To date, a definitive treatment modality for pure ovarian choriocarcinomas has not been established due to the low incidence. Therefore, pure ovarian choriocarcinomas are generally treated with the same protocols that are used for ovarian germ cell tumors and gestational trophoblastic disease. In the current case, 
treatment included debulking surgery followed by adjuvant chemotherapy.

\section{Conclusion}

Non-gestational choriocarcinoma is an extremely rare malignant neoplasm that can present clinically as an acute abdomen and requires differential diagnoses. Management is the combination of surgery and adjuvant chemotherapy, our patient responded well; for women with a desire to preserve fertility, it is a viable option.

\section{References}

1. Yu X, Du Q, Zhang X, Liu Y, Shen Y (2021) Pure primary non-gestational choriocarcinoma originating in the ovary: A case report and literature review. Rare Tumors 13: 20363613211052506. Link: https://bit.ly/3JegejS

2. Jia N, Chen Y, Tao X, Ou E, Lu X, et al. (2017) A gestational choriocarcinoma of the ovary diagnosed by DNA polymorphic analysis: a case report and systematic review of the literature. J Ovarian Res 10: 46. Link: https://bit.ly/3pp4hQp

3. Haruma T, Ogawa C, Nishida T, Kusumoto T, Nakamura K, et al. (2015) Pure choriocarcinoma of the ovary in Silver-Russell syndrome. Acta Med Okayama 69: 183-188. Link: https://bit.ly/3pohZmH

4. Lin L, Yang K, Wu H, Lou J, Peng Z, et al. (2011) Pure choriocarcinoma of the ovary: a case report. J Gynecol Oncol 22: 135-139. Link: https://bit.ly/30Y5qFm

5. Hayashi S, Abe Y, Tomita S, Nakanishi Y, Miwa S, et al. (2015) Primary nongestational pure choriocarcinoma arising in the ovary: a case report and literature review. Oncol Lett 9: 2109-2111. Link: https://bit.ly/3suKEI

6. Kong B, Tian YJ, Zhu WW, Qin YJ (2009) A pure nongestational ovarian choriocarcinoma in a 10-year-old girl: case report and literature review. J Obstet Gynaecol Res 35: 574-578. Link: https://bit.ly/3ej3REW

7. Yamamoto E, Ino K, Yamamoto T, Sumigama S, Nawa A, et al. (2007) A pure nongestational choriocarcinoma of the ovary diagnosed with short tandem repeat analysis: case report and review of the literature. Int J Gynecol Cancer 17: 254-258. Link: https://bit.ly/3Je74nA

8. Fisher RA, Newlands ES, Jeffreys AJ, Boxer GM, Begent RH, et al. (1992) Gestational and nongestational trophoblastic tumors distinguished by DNA analysis. Cancer 69: 839-845. Link: https://bit.ly/32wFmBq

9. Wang Q, Guo C, Zou L, Wang Y, Song X, et al. (2016) Clinicopathological analysis of non-gestational ovarian choriocarcinoma: report of two cases and review of the literature. Oncol Lett 11: 2599-2604. Link: https://bit.ly/330zPH7

10. Yamamoto E (2009) Ovary: Choriocarcinoma. Atlas Genet Cytogenet Oncol Haematol 13: 683-685. Link: https://bit.ly/3qFkVej

11. Heo EJ, Choi CH, Park JM, Lee JW, Bae DS, et al. (2014) Primary ovarian choriocarcinoma mimicking ectopic pregnancy. Obstet Gynecol Sci 57: 330333. Link: https://bit.ly/3elDqyv

12. Saito M, Azuma T, Nakamura K (1963) On ectopic choriocarcinoma. World Obstet Gynecol 17: 459-484.
13. Rao KV, Konar S, Gangadharan J, Vikas V, Sampath S (2015) A pure nongestational ovarian choriocarcinoma with delayed solitary brain metastases: Case report and review of the literature. J Neurosci Rural Pract 6: 578-581. Link: https://bit.ly/3FquROR

14. Hu T, Yang $M$, Zhu $H$, Shi G, Wang $H$ (2011) Pure non-gestational ovarian choriocarcinoma in a 45,XO/46,XX SRY-negative true hermaphrodite. J Obstet Gynaecol Res 37: 1900-1905. Link: https://bit.ly/3FqvQi5

15. Heo JE, Choi CH, Park JM, Lee JW, Bae DS, et al. (2014) Primary ovarian choriocarcinoma mimicking ectopic pregnancy Obstet Gynecol Sci 57: 330333. Link: https://bit.ly/3Je6XIG

16. Serno J, Zeppernick F, Jäkel J, Schrading S, Maass N, et al. (2012) Primary pulmonary choriocarcinoma: Case report and review of the literature. Gynecol Obstet Invest 74: 171-176. Link: https://bit.ly/3mugCRG

17. Low HJJ, llancheran A, Ng JS (2012) Malignant ovarian germ cell tumours Best Pract Res Clin Obstet Gynaecol 26: 347-355. Link: https://bit.ly/3yTznTo

18. Alomar A, Moreno R, Usandizaga M (2005) Coriocarcinoma: un reto para el clínico y el patólogo. Prog Obtet Ginecol 48: 91-96. Link: https://bit.ly/3Jfl6oX

19. Vargas Hernández VM, Vargas-Aguilar VM, Acosta-Altamirano G, GarcíaRodríguez FM, Jiménez-Villanueva X, et al. (2011) Tumores de células germinales. En: Vargas-Hernández VM (ed.). Cáncer en la mujer. México: Alfil 1107-18. Link: https://bit.ly/3yT5oex

20. Lin Lv, Yang K, Wu H, Lou J, Peng Z (2011) Pure choriocarcinoma of the ovary: a case report. J Gynecol Oncol 22: 135-139. Link: https://bit.ly/33V4iU5

21. Choi YJ, Chun KY, Kim YW, Ro DY (2013) Pure nongestationa choriocarcinoma of the ovary: a case report. World J Surg Oncol 11: 7. Link: https://bit.ly/3elDn5N

22. Jia N, Chen Y, Tao X, Ou E, Lu X, et al. (2017) A gestational choriocarcinoma of the ovary diagnosed by DNA polymorphic analysis: a case report and systematic review of the literature. J Ovarian Res 10: 46. Link: https://bit.ly/3yu2eqT

23. Dhanushkodi M, Ganesan T, Sagar TG (2017) Refractory Choriocarcinoma: Complete Response With Oral Etoposide. J Glob Oncol 3: 678-679. Link: https://bit.ly/3H8lwvA

24. Jiao LZ, Xiang Y, Feng FZ, Wan XR, Zhao J, et al. (2009) Ovarian non-gestational choriocarcinoma clinical analysis of 21 cases. Chin J Prac Gynecol Obstet 25:359-361.

25. Anjum A, Maqsood H, Younus S, Anjum S, Fatima M (2021) A Rare Case of Non-Gestational Metastatic Ovarian Choriocarcinoma: Case Report and Literature Review With a Special Emphasis on Imaging. Cureus 13: e13121. Link: https://bit.ly/3H77HOi

26. Rao KV, Konar S, Gangadharan J, Vikas V, Sampath S (2015) A pure nongestational ovarian choriocarcinoma with delayed solitary brain metastases: Case report and review of the literature. J Neurosci Rural Pract 6: 578-581. Link: https://bit.ly/30Yx59c

27. Garrett A, Knehans A, Phaeton R, Kesterson JP (2017) Coriocarcinoma de ovario no gestacional puro: una revisión de alcance. Integr Cancer Sci Therap 4. 